ELEOS: Jurnal Teologi dan Pendidikan Agama Kristen

Sekolah Tinggi Teologi Kalvari Manado

ISSN 2798-9771 (Online), 2798-9860 (Print)

Volume. 1, Nomor. 2, Edisi Januari 2022 (Hal. 99-110)

DOI: $10.53814 /$ eleos.v1i2.6

https://sttkalvari.ac.id/ojs/index.php/eleos/index

\title{
Polemik Memakan Darah: Studi Kasus dalam Sidang di Yerusalem
}

\author{
Jefrie Walean \\ Sekolah Bala Keselamatan Palu \\ jefrywalean@gmail.com
}

\begin{abstract}
This study aims to find answers to the controversy about halal and haram eating blood based on investigations in the trial in Jerusalem. The polemic of eating blood has become a theological controversy among Christians from time to time. Controversy due to differences of opinion because it has a background of diverse theological assumptions. This polemic can actually be resolved if the relational perception is a win-win solution. Is in today's life the prohibition on eating blood in the Old Testament still applies and is it still a disaster for mankind? This study uses a qualitative method with library research and analysis using the principles of hermeneutic interpretation. This study concludes that the doctrinal culmination point related to the blood-eating polemic is one of the factors that breaks relations between Christian groups so that it becomes an interesting "hot" issue.
\end{abstract}

Keywords: Polemic, Prohibition, Eating, Blood

\begin{abstract}
Abstrak: Penelitian ini bertujuan untuk menemukan jawaban kontroversi tentang halal dan haram makan darah berdasarkan penelusuran dalam sidang di Yerusalem. Polemik makan darah telah menjadi kotroversi teologis dikalangan Kristen dari masa ke masa. Kontroversi akibat perbedaan pendapat karena memiliki latar belakang asumsi teologis yang beragam. Polemik ini sejatinya dapat diselesaikan jika persepsi relasional yang bersifat win-win solution. Apakah dalam kehidupan sekarang larangan memakan darah dalam Perjanjian Lama masih berlaku dan masih masih merupakan suatu kebinasaan bagi umat manusia? Penelitian ini menggunakan metode kualitatif dengan riset pustaka dan analisa menggunakan prinsip-prinsip penafsiran hermeneutik. Penelitian ini menyimpulan titik kulminasi doktrinal terkait polemik makan darah menjadi salah satu pemecah hubungan antar golongan orang Kristen sehingga menjadi isu yang menarik.
\end{abstract}

Kata Kunci: Polemik, Larangan, Makan, Darah 


\section{Pendahuluan}

Salah satu kontroversi dikalangan orang kristen adalah polemik Halal dan haram memakan darah. Halal dan haram tertulis secara spesifik ada dalam kitab Imamat pasal 11:1-47. Kitab Imamat ini ditulis oleh Musa. Di dalam pasal ini terdapat beberapa hewan yang dilarang untuk dimakan atau disebut haram. Ciri-ciri hewan yang disebut haram adalah yang memamah biak tapi tidak berkuku belah dan sebaliknya, contoh hewan tersebut adalah unta, kelinci, pelanduk, babi dan lain-lain. "Darah berkaitan dengan kehidupan dan dalam pandangan sang pencipta darah berarti berkaitan dengan kehidupan ini bukan sekadar peraturan mengenai makanan, prinsip moral tersangkut dengan mengerti apa yang Allah firmankan tentang darah terlihat betapa besar nilai darah menyelamatkan kehidupan"2 Apakah rasul-rasul lain mengajarkan terkait larangan makan darah? Polemik masa kini mengalami distorsi sehingga tidak banyak yang mengulas terkait polemik boleh dan tidaknya makan darah dan meminumnya Dalam teks terjemahan baru tidak ada kata makan. Di terjemahan lain juga tidak ada kata makan. Jika dimakan, apakah bisa membuat seseorang lebih rohani dan menambah atau mengurangi kasih karunia Tuhan? Dan jika tidak dimakan, apakah itu bisa menggantikan kebaikan Tuhan? Karena itu, hal ini membutuhkan penyorotan khusus.

Selanjutnya larangan untuk makan makanan yang dipersembahkan kepada berhala, binatang yang mati lemas/dicekik, dan darah memiliki tingkat pelarangan dengan alasan dalam Kisah 15:21 "Sebab sejak zaman dahulu hukum Musa diberitakan di tiap-tiap kota, dan sampai sekarang hukum itu dibacakan tiap-tiap hari Sabat di rumah-rumah ibadat."Pemberitaan dan pembacaan secara terus menerus dari hukum Taurat, yang jelas mencakup larangan makan darah menyebabkan orang-orang Yahudi jijik dengan perbuatan itu memakan darah. Orang-orang Yahudi Kristen membutuhkan suatu proses untuk bisa mengerti dan menerima bahwa aturan Taurat itu sudah dihapuskan. Sebelum hal ini bisa terjadi, mereka tetap akan jijik terhadap orang-orang yang makan hal-hal tersebut. Supaya ada hubungan yang baik antara Yahudi dan non Yahudi, maka orang non Yahudi sebaiknya tidak makan apa yang menjijikkan bagi orang Yahudi. Syarat-syarat yang ditetapkan adalah berkaitan dengan pergaulan sosial yang terutama mengenai hukum tentang makanan, yang mudah menjadikan hal tersebut suatu batu sandungan bagi orang-orang kalangan Yahudi yang masih berpegang teguh kepada peraturan Taurat. Jadi jelas bahwa larangan ini hanya berlaku untuk situasi dan kondisi itu saja, dan tidak berlaku untuk kita disini pada zaman ini. Memaknai Kisah 15:20,29 dan 21:25 tentu akan kontradiksi dengan Pernyataan Tuhan Yesus yang telah menghalalkan semua makanan. Jawab Yesus dalam Markus 7:18-19"Apakah kamu juga tidak dapat memahaminya? Tidak tahukah kamu bahwa segala sesuatu dari luar yang masuk ke dalam seseorang tidak dapat menajiskannya. Isu percabulan ini sesuatu yang umum bagi orang non Yahudi karena sering berhubungan dengan agama kafir sehingga dianggap tidak dosa. Kontroversi yang terjadi di kalangan umat Kristen adalah

${ }^{1}$ Adi Asmara, “Tinjauan Biblika Terhadap Kontroversi Halal Dan Haram Vaksin Covid-19," Jurnal Teologi Biblika 6, no. 1 (2021): 37-42.

2 Ayuda Berliana, "Darah Dalam Pandangan Kristen," Https://Repository.Uinjkt.Ac.Id. 
mengenai hal-hal ini termasuk di dalamnya larangan mengenai memakan darah. Dasar dari pemahaman tentang memakan darah adalah haram terdapat pada Kejadian 9:4 Hanya daging yang masih ada nyawanya, yakni darahnya, janganlah kamu makan. Banyak umat Kristen sebenarnya memiliki pemahaman yang salah mengenai ayat ini mengenai penafsiran tidak boleh memakan darah karena hukumnya haram. Namun sebenarnya ayat ini menjelaskan bahwa manusia dilarang oleh Allah untuk memakan hewan dalam keadaan hidup (kanibal). ${ }^{3}$ Dalam agama Yahudi dengan basis Taurat (Perjanjian Lama) "dianggap" Allah yang sama dengan perspektif baru, maka sejatinya masih relevankah meminta orang melakukan konversi pada tatanan luar. Pada intinya Yudaiisme berusaha mengartikulasikan teologi taurat sebagai landasan hukum Tetapi dilain pihak aspek ritual dianggap tida relevan bagi non Yahudi. Perspektif hukum kebaruannya ialah perspektif noia yang baru.

Pemahaman secara komprehensif mengenai kontroversi mengenai hukum halal dan haram masa kini bukan hanya dari sudut pandang kekristenan melainkan dari sudut pandang secara publik. Masyarakat Ibrani dan para imam disucikan dengan darah yang dipercikkan di atas mezbah penebusan dosa dan darah juga dipercikkan ke atas semua orang Israel untuk membuat perjanjian dengan Tuhan. Kultur Indonesia, tidak ada pemahaman bahwa darah terkait nyawa manusia, sehingga makan darah bukan menjadi masalah teologis. Telhalia, menulis, Dalam Perjanjian Lama, pengertian darah (Ibrani = dam, Yunani = raima), yaitu kata yang berhubungan dengan cairan hidup dalam tubuh manusia. Ada sesuatu yang suci yang melekat pada darah, sebab darah merupakan kesatuan dengan jiwa, sebagaimana dalam Kitab Imamat 17:14, "Darah adalah nyawa segala makhluk." Misalnya, tentang penghargaan terhadap darah, terdapat di dalam kitab Kej 4:10, "Darah adikmu berteriak kepada-Ku." Kain telah menumpahkan darah saudaranya yang mengakibatkan kematian adiknya. Darah yang ditumpahkan itu berseru kepada Allah memohonpembalasan. Allah tidak menginginkan pertumpahan darah, oleh sebab itu kepada Kain dikatakan bahwa apabila terjadi penumpahan darah akan terjadi penuntut balas darah $\left(\right.$ Kej 4:15) ${ }^{4}$

Dalam Perjanjian Lama, manusia mencari keselamatan mereka melalui pengorbanan yang dibuat dari darah hewan, jadi Tuhan melarang orang Israel makan darah, lalu bagaimana dengan kehidupan sekarang? Manusia telah ditebus dari dosanya dan keselamatan dijamin di dalam Yesus Kristus, tetapi masih ada orang yang percaya. Yesus menyatakan bahwa dilarang makan darah. Apakah dalam kehidupan sekarang ini larangan makan darah dalam Perjanjian Lama masih berlaku dan masih merupakan pemusnahan bagi umat manusia? Tidak ada superioritas ke Yahudian dalam Perjanjian baru termasuk yudaisme. Paulus mengkritik Yudaisme dalam suratnya kepada jemaat di Galatia. Ada pandangan bahwa pada zaman sekarang larangan makan darah itu sudah tidak berlaku. Keputusan bahwa larangan makan darah juga berlaku bagi kaum di luar Yahudi telah mengangkangi hak non Yahudi untuk bisa makan makanan yang dianggap

\footnotetext{
3 Asmara, "Tinjauan Biblika Terhadap Kontroversi Halal Dan Haram Vaksin Covid-19."

4 Telhalia, "Teologi Kontekstual Pelaksanaan Jalan Hadat Perkawinan Dayak Ngaju Di Gereja Kalimantan Evangelis," Jurnal Studi Agama-Agama 6, no. 2 (2016): 230-252.
} 
haram oleh orang Yahudi. Pada akhirnya kontekslah yang menjelaskan mengapa larangan ini dianggap hasil sidang di Yerusalem.

\section{Metode Penelitian}

Riset ini bertujuan untuk mengulas multi perspektif terkait makan darah. Data primer penelitian ini ialah studi pustaka melalui metodologi kualitatif dengan pendekatan Integrative Critical Analysis (ICA), dan analisis eksegese deskriptif. Pendekatan ICA dilakukan karena isu sentral pembahasan ini terletak kepada boleh dan tidak boleh memakan darah. Data pustaka yang terkumpul dianalisa Selanjutnya diverifikasi selanjutnya disimpulkan. Data eksegesa menggunakan metode hermeneutic, Dalam hermeneutik tersebut yang diangkat ke permukaan adalah yang negatifnya, supaya jangan yang negatif itu juga dianggap yang dikehendaki Allah.

\section{Hasil dan Pembahasan}

\section{Konteks Perjanjian Lama}

Konteks Perjanjian Lama "darah" dalam pemikiran Ibrani adalah tempat pusat "kehidupan" atau bahkan diidentikkan dengan pusat kehidupan itu sendiri. Karena itu, darah merupakan sesuatu yang sangat memiliki peranan penting dalam persembahan "korban" yang dalam masyarakat Ibrani sangat fundamental. Para imam dikuduskan dengan dara yang dipercikkan ke atas mezbah penebus dosa dan juga darah dipercikkan kepada seluruh umat Israel untuk menegakkan perjanjian dengan Tuhan. Kitab ini terdiri dari hukum dan peraturan. Kitab Imamat melanjutkan sejarah dalam Kitab Keluaran terkait ketetapan Allah. Imamat berarti berhubungan dengan imam atau orang Lewi. Dalam bahasa Ibrani, kitab ketiga Taurat disebut wayiqra yang artinya (begitulah Dia memanggil atau Dia memanggil). Imamat 11:1-47 terdapat beberapa hewan yang dilarang untuk dimakan atau disebut haram. Ciri-ciri hewan yang disebut haram adalah yang memamah biak tapi tidak berkuku belah dan sebaliknya, contoh hewan tersebut adalah unta, kelinci, pelanduk, babi dan lain-lain. Kejadian 9:4: Hanya daging yang masih ada nyawanya, yakni darahnya, janganlah kamu makan (Imamat 3:17; 7:26; Ulangan $12: 23 ; 15: 23)$.

\section{Polemik dalam sidang di Yerusalem}

Beberapa orang datang dari Yudea ke Antiokhia dan mengajarkan kepada saudara-saudara di situ: "Jikalau kamu tidak disunat menurut adat istiadat yang diwariskan oleh Musa, kamu tidak dapat diselamatkan."15:2 Tetapi Paulus dan Barnabas dengan keras melawan dan membantah pendapat mereka itu. Akhirnya ditetapkan, supaya Paulus dan Barnabas serta beberapa orang lain dari jemaat itu pergi kepada rasul-rasul dan penatua-penatua di Yerusalem untuk membicarakan soal itu. Polemik ini mendorong dilaksanakan sidang gereja Yerusalem. Dan dalam perundingan untuk memutuskan siapa yang benar, Yakobus lalu memberikan pandangannya yang nantinya diterima sebagai keputusan sidang. Dalam persidangan di Yerusalem yang tercatat di Kisah Para Rasul 15, kita bisa melihat ajaran soal makanan halal- 
haram dalam konteks Yahudi. Dalam sidang di Yerusalem, salah satu rasul yaitu Petrus sudah memperoleh penglihatan jelas dalam Kisah 11:5-10 dalam kasus Kornelius. Sikap Petrus masih sering lemah yang ikut-ikutan adat Yahudi pengikut Yakobus (Kisah 21:15-26) hingga dikritik Paulus. Robi Prianto, Kezia Lawira, Novianto menulis, "Ciri-ciri Yudaisme adalah melakukan apa yang menjadi tuntutan hukum Taurat, adat istiadat dan moralitas merupakan bagian dari ibadah mereka. Orang-orang Yahudi mengakui bahwaYahweh adalah satu-satunya Allah. Orang Yahudi juga berusaha semaksimal mungkin dalam menjalani kewajiban Taurat terutama dalam hal sunat, menaati hari Sabat dan tidak memakan makanan yang dianggap haram"5 Waktu itu para Rasul memahami bahwa larangan memakan darah merupakan uraian aturan taurat Musa yang tetap menjadi rules bagi orang Yahudi. Polemik mengkonsumsi darah menjadi perdebatan sehingga mereka dapat makan segala macam makanan kecuali (waktu itu) mereka masih membatasi pada makanan yang tidak tercemar berhala dan daging binatang yang tercekik. Ia mendukung Petrus dengan ayat-ayat Kitab Suci/Perjanjian Lama. Ayat 15-18 ia kutip dari Amos 9:11-12 (tidak dikutip persis/kata per kata), yang menubuatkan bahwa orang-orang non Yahudi akan menjadi milik Tuhan.Ayat 19: ia beranggapan bahwa mereka tidak boleh memberikan kesulitan kepada orang-orang non Yahudi yang menjadi orang kristen (dengan mengharuskan sunat, Ini sejalan dengan kata-kata Petrus dalam sidang yang sama, yaitu dalam Kisah 15:10 "Kalau demikian, mengapa kamu mau mencobai Allah dengan meletakkan pada tengkuk muridmurid itu suatu kuk, yang tidak dapat dipikul, baik oleh nenek moyang kita maupun oleh kita sendiri?".Ayat 20-21: ia menegaskan larangan makanan yang telah dipersembahkan kepada berhala arena berkaitan dengan daging binatang yang mati dicekik dan darah. Konteks waktu itu adalah pertentangan antara Paulus dan Barnabas terkait status atau posisi teologis orang Yahudi Kristen dan non Yahudi kristen.

\section{Hukum Moral Dan Seremonial Yahudi}

Dalam konteks sidang di Yerusalem, terdabat ambigu dikalangan masyarakat Yahudi terkait pembatas yudaisme dan Kristen dalam ritual keagamaan. Para rasul menjadi sangat sensitif karena sempat dianiaya oleh pengikut "Yudaisme radikal pasca kotbah Petrus." Larangan makan darah masuk hukum seremonial atau moral? Orang Yahudi tidak membedakan seremonial/ritual dengan moral/etis. Halmemakan darah terkesan esensial tapi aksesoris karena bagi orang Yahudi harus tetapi non Yahudi tidak harus. Pelaksanaan ritual itu mengandung nilai-nilai moral. Dan yang moral itu disimbolkan dengan ritual. Ritual kurban di perjanjian lama misalnya, jangan tidak secara linier sudah digenapi dalam pengorbanan Yesus. Ritual kurban itu sendiri mengandung nilai etis bahwa segala sesuatu tertata dengan baik. Dalam Alkitab Ibrani Biblia Herbaica Stuttgartensia, kata "kebenaran" atau righteousness (Kej. 15:6; U1. 25:1) dari kata צ צ९ה(tsedaqa). Kata ini adalah satu kata yang dipakai dalam hukum, mengandung pengertian yuridis atau forensik, yang bermakna menyatakan atau

\footnotetext{
${ }^{5}$ Robi Prianto, Kezia Lawira, and Novianto Novianto, “Makna 'Injil Yang Lain’ Dalam Galatia 1: 6-7,” TE DEUM (Jurnal Teologi Dan Pengembangan Pelayanan) 10, no. 2 (2021): 205-226.
} 
mendeklarasikan benar sesuai dengan hukum. ${ }^{6}$ Dalam Perjanjian Lama kurban tetap yaitu kurban rutin setiap pagi dan petang. Kalaupun itu sifatnya lokal, tetap saja itu bentuk kekerasan terhadap yang non-Yahudi di lokal tersebut. Binatang-binatang yang dikorbankan pada zaman Perjanjian Lama tidak boleh binatang yang masih bayi tetapi sudah cukup umur. Dalam konteks Perjanjian Lama, darah binatang sebagai simbol menebus dosa perbuatan manusia.

Hukum moral seperti kuduskanlah hari sabat, jangan membunuh tetap berlaku sampai sekarang. yang seremonial seperti tangan dipotong kalau berbuat salah/dosa maka hukum memakan darah tetaperjanjian lamaah sebuah aturan. Tapi yang moral tetap berlaku sampai sekarang. Keputusan sidang di Yerusalem merupakan "pengebirian” kebebasan orang kristen non Yahudi dalam rangka membela kepentingan orang kristen Yahudi. Selanjutnya Robi Prianto, Kezia Lawira, Novianto menulis, Orang-orang Kristen Yahudi memaksa orang-orang Kristen non-Yahudi untuk menaati Taurat agar mendapatkan pembenaran. ${ }^{7}$ Orang kristen Yahudi yang masih memegang teguh tradisi tauratnya lebih dibela oleh para rasul dari pada orang non Yahudi dan harus mengalah. Rasul-rasul masih berpikir Yahudi sentris. Dan hal itu diategorikan berpikir ambigu. Untuk memahaminya perlu melihat dengan utuh agar klaim larangan bersifat situasional atau lokal sehingga tidak wajib berlaku bagi non Yahudi.

\section{Apakah Keputusan Roh Kudus Tidak Boleh Memakan Darah”}

Roh Kudus memberikan hikmat kepada para rasul untuk mengambil keputusan yang bijak dari kondisi yang pelik itu. Terbukti bahwa tidak ada masalah yang berarti tentang keputusan itu kelak. Keputusan Roh Kudus agar tidak memakan makanan yang dipersembahkan kepada berhala karena aturan taurat. Sebab adalah keputusan Roh Kudus dan keputusan kami, supaya kepada kamu jangan ditanggungkan lebih banyak beban dari pada yang perlu ini bahwa kamu harus menjauhkan diri dari makanan yang dipersembahkan kepada berhala, dari darah, dari daging binatang yang mati dicekik dan dari percabulan. Jikalau kamu memelihara diri dari halhal ini, kamu berbuat baik. Jika keputusan Roh Kudus hal ini pun dilanggar dengan dalil-dalil gagal paham memahami taurat. Kisah Para Rasul 15:28-29 (ILT) Sebab rupanya Roh Kudus dan kami tidak meletakkan ke atas kamu beban yang lebih berat lagi daripada yang diperlukan untuk menjauhkan diri dari sesuatu yang dikorbankan kepada berhala, dan dari darah, dan dari binatang yang mati tercekik, dan percabulan, yang ketika menjauhkan dirimu sendiri dari padanya, maka kamu berbuat baik. Baik-baiklah kamu!" Bukan "meminjam otoritas Roh Kudus" agar ditaati, sebagian orang non Yahudi juga tidak melakukan protes pada saat sidang di Yerusalem. Keputusan-keputusan tersebut hanya dipakai saja untuk "membungkam"karena "kewibawaan" para rasul yang berlatarbelakang Yudaisme. Analogi dapat digambarkan pihak yang saling mengalah.

Dalam rangka melegitimasi keputusan rapat tersebut agar dipatuhi jemaat, maka keputusan itu dianggap keputusan Roh Kudus. Kemungkinan putusan sidang di Yerusalem itu

${ }^{6}$ Suyadi Tjhin, "Ajaran Tentang Pembenaran Menurut Paulus Dan Yakobus, Serta Signifikansinya Bagi Pemahaman Soteriologis," Jurnal EFATA: Jurnal Teologi dan Pelayanan 7, no. 2 (2021): 82-93.

${ }^{7}$ Prianto, Lawira, and Novianto, "Makna 'Injil Yang Lain' Dalam Galatia 1: 6-7." 
adalah bentuk pengebirian kebebasan orang kristen non Yahudi dalam rangka membela kepentingan orang kristen Yahudi. Orang kristen Yahudiyang masih memegang teguh tradisi tauratnya lebih dibela oleh para rasul dari pada orang non Yahudi. Maka yang non Yahudi disuruh mengalah bukan sebaliknya orang Yahudi yang diberi pengertian. Mengapa polemik pemaksaan itu bisa terjadi? Karena para rasul sendiri masih berpikir Yahudi sentris. Sebenarnya pikirannya masih selaras dengan jemaat Yahudi, maka tidak bisa bersikap yang adil. Praktikpraktik itu biasa di kalangan kita, mengatasnamakan Firman Tuhan, Roh Kudus, tetapi sebenarnya ada kepentingan lainnya yang sedang diperjuangkan.

\section{Konteks Paulus}

Keputusan itu lokal tak ada perintah lain termasuk surat-suratPaulus lainnya karena kita yakin tulisan Paulus juga Roh. Ketika Paulus menulis surat-suratnya, para pembaca dan pendengar didominasi oleh masyarakat non Yahudi yang menghalalkan makanan termasuk darah. Hal ini menarik karena asumsinya bahwa Jika darah itu tidak boleh dimakan pasti dalam surat surat ia melarang, Tetapi tidak ada larangan. Prinsip Paulus, walaupun dia bebas untuk makan atau tidak makan sesuatu, tapi demi iman orang yang lemah "mending" tidak usah makan. Tetapi segala hal yang tidak baik diputuskan Roh Kudus tidak boleh dilakukan. Yang tidak dibolehkan Roh Kudus adalah yang berkaitan dengan berhala. Tapi hal membawa-bawa nama Roh Kudus atau Firman Allah. Tapi masalahnya ini keputusan rapat, bukan pedagogi sehingga yang dipermasalahkan adalah keadilan bagi masyarakat non Yahudi. Perspektif Paulus tentang status makanan yang dipersembahkan ke berhala. Orang non Yahudi menjadi kristen bukan untuk menjadi orang Yahudi. Jadi seharusnya aturan yang haram bagi orang Yahudi tidak perlu diberlakukan sama sekali kepada non Yahudi. Kalau masih ada, meskipun itu cuma satu saja, itu berarti kerangka berpikirnya adalah menjadikan mereka orang Yahudi dengan memberi toleransi. Menyeimbangkan nomianisme dan anti nomianisme sebagai jalan tengah memahami secara komprehensif polemik dalam sidang di Yerusalem yang didominasi oleh kristen Yahudi radikal. Ketegangan relasi yang sempat terjadi saat makin banyak orang non Yahudi bergabung ke gereja yang masih mayoritas Yahudi ketika itu. Penjelasan Paulus terkait bagian ini dapat dianalisa sebagai berikut

Pembenaran berarti "menyatakan benar" bukan "menjadikan benar," dan terjadi ketika seseorang menyatakan dirinya percaya kepada Kristus. Pembenaran merupakan sesuatu yang bersifat status hukum bukan bersifat proses etika. Yakobus tidak bermaksud bersikap antitesis terhadap apa yang Diajarkan Pembenaran, baik hitsdiq maupun dikaioo (justify atau ighteousness) lebih ditujukan pada arti "menyatakan benar" bukan "menjadikan benar". Kata ini lebih tertuju pada "status hukum" dari pada menjadikan seseorang punya "kualitas etika. ${ }^{8}$

Konteks keputusan Yerusalem beda dengan kasus di Korintus. Jadi jangan hanya membacalarangan yang masih diberlakukan, tapi mengabaikan ratusan yang dibatalkan. Jangan

8 Tjhin, "Ajaran Tentang Pembenaran Menurut Paulus Dan Yakobus, Serta Signifikansinya Bagi Pemahaman Soteriologis." 
lupa bahwa kesaksian ahli yaitu Paulus yang pakar Taurat sekaligus rasul untuk orang non Yahudi adalah pendapat paling dominan dalam menentukan keputusan sidang sinode Yerusalem dan Yakobus hanya merangkumnya, Bagaimana mungkin Paulus mengajukan proposal yang kelak akan mengkerdilkan peran dan pelaksanaan misinya? salah satu dari butir larangan itu pun kelak dia "langgar" yaitu tentang makan makanan yang dipersembahkan kepada berhala di jemaat jemaat Korintus). Rasul Paulus menyuruh Timotius meminum anggur agar tidak lemah tubuh dan pencernaannya (1 Timotius 5:23) Jikalau berdasarkan ayat-ayat dalam Kisah Rasul itu ditarik kesimpulan bahwa makan darah terus dilarang sampai sekarang, maka konsekuensinya adalah bahwa makan daging yang dipersembahkan kepada berhala juga harus dilarang pada zaman ini. Tetapi ini jelas tidak benar, karena dalam 1 Korintus 8 dan 1 Korintus 10 terlihat bahwa makan daging yang dipersembahkan kepada berhala sebetulnya tidak apa-apa (lihat ayat-ayat tersebut yang sudah dikutip di atas). Kalau dalam situasi dan kondisi tertentu kita dilarang makan, itu bukan karena dagingnya sendiri, tetapi supaya tidak menjatuhkan orang lain ke dalam dosa. Menurut Paulus Aku tahu dan yakin dalam Tuhan Yesus, bahwa tidak ada sesuatu yang najis dari dirinya sendiri. Hanya bagi orang yang beranggapan, bahwa sesuatu adalah najis, bagi orang itulah sesuatu itu najis. Paulus"mengutip" semboyan umum yang dipakai oleh orang-orang di Korintus untuk membenarkan tingkah laku mereka.

Dalam 1 Korintus 6:12-20Segala sesuatu halal bagiku, tetapi bukan semuanya berguna. Segala sesuatu halal bagiku, tetapi aku tidak membiarkan diriku diperhamba oleh suatu apapun. Makanan adalah untuk perut dan perut untuk makanan: tetapi kedua-duanya akan dibinasakan Allah. Tetapi tubuh bukanlah untuk percabulan, melainkan untuk Tuhan, dan Tuhan untuk tubuh. Tekanan Paulus untuk menjauhkan dirimu dari percabulan! Setiap dosa lain yang dilakukan manusia, terjadi di luar dirinya. Tetapi orang yang melakukan percabulan berdosa terhadap dirinya sendiri termasuk konsep "menghargai" tubuh yang telah dibeli dan harganya telah lunas dibayar: Karena itu muliakanlah Allah dengan tubuhmu. Para penafsir tidak mengubungkan langsung dengan larangan makan darah hewan. Namun demikian, bagaimanakah kita memperlakukan kemerdekaan kita ini? Lebih lanjut dikatakan dalam Galatia 5:13 "Saudara-saudara, memang kamu telah dipanggil untuk merdeka. Tetapi janganlah kamu mempergunakan kemerdekaan itu sebagai kesempatan untuk kehidupan dalam dosa, melainkan layanilah seorang akan yang lain oleh kasih.

Ada dua konsep yang perlu dipertimbangan terkait diskursus larangan sebagai hukum dan etika dalam surat Galatia menekankan kepada orang Kristen non-Yahudi untuk melakukan adat istiadat Yahudi yang disebut dengan Halakha. Paulus dalam surat Galatia menyebutnya sebagai nomos (hukum) yang menjadi suatu kewajiban yang harus dilakukan bagi orang Yahudi. Dalam peraturan tersebut, hal-hal yang wajib dilakukan seperti sunat, hari-hari tertentu dan peraturanperaturan lainnya dengan tujuan untuk memperoleh kesempurnaan dihadapan Allah agar bisa diselamatkan ${ }^{9}$ Sebagai umat percaya kita dipanggil untuk hidup dalam kemerdekaan dengan hati nurani yang bebas dari penghukuman. Kita tidak perlu lagi sibuk dengan urusan

\footnotetext{
${ }^{9}$ Prianto, Lawira, and Novianto, “Makna 'Injil Yang Lain’ Dalam Galatia 1: 6-7.”
} 
membedakan apa yang boleh/tidak boleh dengan cara sebagaimana orang Yahudi sibuk melaksanakan Taurat secara lahiriah. Jadi hukum Taurat adalah penuntun bagi kita sampai Kristus datang, supaya kita dibenarkan karena iman." Peraturan boleh/tidak boleh di dalam Hukum Taurat hanya diperuntukan bagi kanak-kanak rohani yang lemah iman. Nasihat rasul Paulus, agar berhati-hati menghadapi semangat ajakan kembali ke akar Yudaisme yang didasarkan pada Taurat dan adat-istiadat Yahudi. Bagi Paulus sentralitas dan finalitas Kristus merupakan kunci keselamatan. Frasa "janganlah kamu biarkan orang menghukum kamu mengenai makanan dan minuman atau mengenai hari raya, bulan baru ataupun hari Sabat" hanyalah bayangan dari apa yang harus datang, sedangkan wujudnya adalah Kristus. Penegasan Paulus kepada gereja-gereja non Yahudi bukan sebagai jalan keselamatan, tetapi sebagai dasar dari persekutuan, dalam roh. Substansi nasehat Paulus bahwa mereka yang kuat dalam iman harus mau membatasi kebebasan mereka dalam hal menyakiti hati saudara yang lebih lemah (Roma 14:1-23; 1 Korintus 8:1-13)].

\section{Moralitas Seremonial Korban Yesus}

Moralitas yang digambarkan dalam Alkitab tentu saja moralitas versi Yahudi. Sebagai hukum moral bisa serta merta berlaku sekarang. Alkitab tentu saja moralitas versi Yahudi. Oleh karena itu Yesus membongkar batas-batas moral yang dibangun oleh pemuka/elit Yahudi seperti misalnya dengan mengampuni perempuan yang kedapatan berzinah, makan di rumah pemungut cukai \& orang berdosa, berbicara dengan perempuan Samaria. yang dilakukan Yesus itu jelas dibaca oleh elit Yahudi sebagai perlawanan terhadap batas-batas kesucian yang mereka buat. Itulah mengapa Yesus menjadi sasaran pembunuhan mereka. Bahwa yang seremonial sudah selesai dengan kematian Kristus di kayu salib. Menjadi murid Yesus bukan sekedar taat akan peraturan, karena Tuhan Yesus lebih menitikberatkan bahwa apapun yang kita lakukan adalah karena kita benar-benar mengasihiNya. Sebagai murid Yesus yang sudah ditebus. Sebaiknya kita tidak terlalu mempermasalahkan haram dan halal makanan dan jangan melakukannya hanya sekedar mentaati peraturan. Kita adalah orang-orang yang merdeka. Sama seperti anak kecil di dalam sebuah keluarga akan diberi peraturan boleh/ tidak boleh oleh orangtuanya. Namun ketika si anak beranjak dewasa, dia tidak lagi terikat akan peraturan boleh/tidak boleh itu karena orang dewasa "mempunyai pancaindera yang terlatih untuk membedakan yang baik dari pada yang jahat" (Ibrani 5:14). Bagi orang dewasa pokok permasalahan bukan pada boleh/tidak boleh tapi pada masalah pantas/ tidak pantas.

Kekristenan bukanlah seperangkat kode etik, peraturan boleh/ tidak boleh, atau filosofi hidup. Kekristenan adalah hubungan yang begitu erat antara Allah dan manusia, sebagaimana Bapa terhadap anak-anaknya dan bahkan lebih intim bagaikan hubungan suami kepada istrinya. Yesus Kristus membawa kita kepada Bapa, lalu mencurahkan Roh Kudus kepada kita, bukan agar kita menjadi orang baik dengan standar moral yang lebih tinggi, tetapi menjadi ciptaan baru, menjadi penyampai pesan Allah, menjadi pecinta Allah, menjadi obor dari darah daging yang dibakar oleh nyala api Roh Tuhan yang hidup. Yesus Kristus telah menyebut dalam Markus 7:19bahwa semua makanan itu sebenarnya halal, dan para murid termasuk Petrus 
mendengar juga ajaran itu. Para murid tidak segera mencernanya karena adat istiadat Yahudi begitu melekat. Bagi Taurat Yahudi, agama Yahudi hanya untuk orang Yahudi saja, namun Yesus menghidupkan Kristianitas/Kehidupan Kristen dimana tidak ada perbedaan antara bangsa Yahudi dan bangsa lain dalam nama Yesus, dan ini diidentikkan dengan tidak adanya perbedaan antara makanan haram dan halal dalam agama. Petrus juga makin teguh dengan keyakinan Injilnya. Berbeda dengan penganut kesucian makanan yang melarang orang minum anggur, Manusia telah ditebus dosanya dan keselamatan dijamin dalam Yesus Kristus, namun masih ada orang yang percaya. Dalam perspektif maka dapat dikonstrusikan bahwa Yesus tidak menetapkan larangan untuk memakan darah.

Dengan demikian bahwa prinsip yang menjadikan hukum yudaiisme yang melarang memakan darah hanya berlaku lokal saja. Namun pemahaman tesisnya yang bersifat alternatif. Penjelasan yuridis Musa untuk menolak memakan darah tidak berlaku secara generatif. Penjelasan Paulus terkait bagian ini dapat dianalisa sebagai berikut

\section{Polemik masa kini}

Aliran dalam agama Kristen ini memiliki banyak perbedaan pemahaman. Contohnya perbedaan pemahaman antara aliran Protestan dan aliran Pantekosta mengenai memakan darah. Ada Yang pro dan ada yang kontra terhadap hal tersebut. Pantekosta mengikuti tradisi Yahudi yang terdapat dalam Perjanjian Lama mengenai larangan memakan darah dan larangan itu sebagai imperjanjian lamaikasi sola scriptura. Prinsip sola scriptura adalah prinsip yang menjadikan Alkitab firman Allah sebagai pusat satu-satunya instrumen Allah untuk memahami dan memberikan kebenaran pribadi dan karya Allah ${ }^{10}$ Bagi pemahaman mereka, darah merupakan nyawa yang hanya dipersembahkan kepada Tuhan dan siapa pun yang memakannya menimbulkan dosa terhadap dirinya sendiri. Namun, bagi aliran Protestan Makan darah bukanlah merupakan suatu dosa dan bukan suatu kekejian bagi Allah. ${ }^{11}$ Perspektif polemik memakan darah dalam ajaran Paulus di jemaat Korintus lebih jelas mengakomodasi ajaran Yesus mengenai semua makanan halal menjadi lebih jelas. Berbeda dengan penganut kesucian makanan yang melarang orang minum anggur. halal merupakan sesuatu yang diperbolehkan dalam syariat Islam untuk dilakukan, dipergunakan, atau diusahakan dan terbebas dari hal yang membahayakan Sedangkan haram berarti sesuatu yang dilarang dengan larangan yang tegas untuk dilakukan atau dipergunakan baik disebabkan karena zatnya maupun cara mendapatkanny ${ }^{12}$ Menurut penelitian yang dilakukan oleh Syahrul, dan Sumardi, Sebagaimana diketahui bahwa sebagian besar masyarakat suku Batak yang berada di Kecamatan Ajibata adalah beragama Kristen sehingga hal tersebut juga turut mempengaruhi jenis makanan yang

${ }^{10}$ Kristina Halawa Imama, "Implementasi Prinsip Sola Scriptra Teologi Reformed,” Manna Rafflesia 5, no. 2 (2019): 120.

11 Yudit Para"Pak, Larangan Makan Darah Dalam Pl Dan Implementasinya Terhadap Pengorbanan Kristus Di Zaman Sekarang (Toraja, 2021).

${ }^{12}$ Atik Abidah, "Tinjauan Mas \}Lah\} Ah Terhadap Larangan Mengkonsumsi Hewan Membahayakan Secara Medis" (IAIN ponorogo, 2021). 
mereka konsumsi sehari-hari. Terkait dengan hal tersebut, secara umum masakan khas suku Batak berbahan daging babi, anjing dan diolah menggunakan darah binatang tersebut dimana hal tersebut diharamkan menurut ajaran Islam. ${ }^{13}$

Perihal makan darah itu hanya berlaku dalam relasi dengan Kristen Yahudi radikal sehingga polemik terkait haram bagi orang Yahudi tidak menjadi penghalang orang kristen luar Yahudi untuk masuk dalam golongan kristen Yahudi. larangan di kisah rasul itu mesti dilihat dari konteks situasinya sehingga ayat-ayat itu tidak berlaku secara universal tapi lebih bersifat lokal. Hal ini cukup adil bagi orang Yahudi karena berkoelasi langsung. Ini orang non-Yahudi bukan mau masuk agama Yahudi sehingga harus memenuhi persyaratan keyahudian dan kemudian dikasih keringanan, tapi mau percaya Yesus tanpa menjadi Yahudi. Disini teologi progresif perlu sekali dipahami.

\section{Kesimpulan}

Dalam sidang di Yerusalem kaum radikal menganggap bahwa mereka memiliki otoritas teologis melakukan perintah Tuhan terkait peraturan keimamatan. Pemaksaan aturan Taurat termasuk turunannya yang dipaksakan oleh kaum Yahudi kepada petobat berlatar non Yahudi, pada akhirnya berhadapan dengan konsep pembenaran oleh iman. Perspektif Yesus dan Paulus tidak menyusun larangan permanen, apalagi jika dikaitkan dengan konsep soteriologis. Penerapan azas praduga tak bersalah dalam menilai polemik ini. Roh Kudus memang membebaskan dan memberikan kebebasan, tetapi bukan kebablasan, seolah tidak perlu hukum lagi. Linieritas keputusan Roh Kudus dan keputusan rasul-rasul sudah tepat agar menjauhkan diri dari makanan yang dipersembahkan kepada berhala, dari darah, dari daging binatang yang mati dicekik dan dari percabulan. Titik kulminasi doctrinal polemik makan darah menjadi salah satu pemecah hubungan antar golongan orang Kristen sehingga menjadi "hot" isu yang menarik. Kontroversi akibat perbedaan pendapat karena memiliki latar belakang asumsi teologis yang beragam. Polemik ini sejatinya dapat diselesaikan jika persepsi relasional yang bersifat win-win solution.

\section{Referensi}

Asmara, Adi. "Tinjauan Biblika Terhadap Kontroversi Halal Dan Haram Vaksin Covid-19." Jurnal Teologi Biblika 6, no. 1 (2021): 37-42.

Atik Abidah. "Tinjauan Mas\}Lah\}Ah Terhadap Larangan Mengkonsumsi Hewan Membahayakan Secara Medis." IAIN ponorogo, 2021.

Ayuda Berliana. "Darah Dalam Pandangan Kristen." Https://Repository.Uinjkt.Ac.Id.

Imama, Kristina Halawa. "Implementasi Prinsip Sola Scriptra Teologi Reformed." Manna Rafflesia 5, no. 2 (2019): 120.

Prianto, Robi, Kezia Lawira, and Novianto Novianto. "Makna 'Injil Yang Lain' Dalam Galatia 1: 6-7.” TE DEUM (Jurnal Teologi Dan Pengembangan Pelayanan) 10, no. 2 (2021):

${ }^{13}$ Syahrul Dan Sumardi, “The Culinary Tourism Destination TraditionalCulinary Based In The Regency OfToba Samosir,” Jurnal Akademi Pariwisata Medan 7, no. 2 (2019): 44. 
Jefrie Walean: Polemik Memakan Darah: Studi Kasus dalam Sidang di Yerusalem

205-226.

Syahrul Dan Sumardi. "The Culinary Tourism Destination TraditionalCulinary Based In The Regency OfToba Samosir.” Jurnal Akademi Pariwisata Medan 7, no. 2 (2019): 44.

Telhalia. "Teologi Kontekstual Pelaksanaan Jalan Hadat Perkawinan Dayak Ngaju Di Gereja Kalimantan Evangelis.” Jurnal Studi Agama-Agama 6, no. 2 (2016): 230-252.

Tjhin, Suyadi. "Ajaran Tentang Pembenaran Menurut Paulus Dan Yakobus, Serta Signifikansinya Bagi Pemahaman Soteriologis." Jurnal EFATA: Jurnal Teologi dan Pelayanan 7, no. 2 (2021): 82-93.

Yudit Para"Pak. Larangan Makan Darah Dalam Pl Dan Implementasinya Terhadap Pengorbanan Kristus Di Zaman Sekarang. Toraja, 2021. 